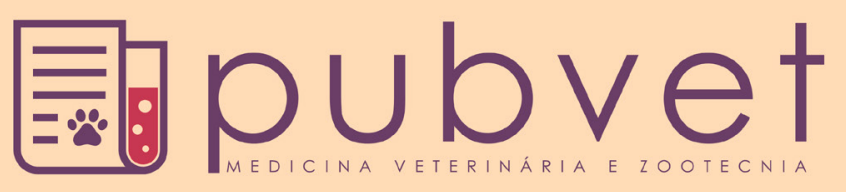

HTTP://DX.DOI.ORG/10.22256/PUBVET.V11N8.808-814

\title{
Adubação nitrogenada e consorciação de Trachypogon plumosus com Stylosanthes capitata cv. Lavradeiro sob diferentes densidades de semeadura
}

\author{
Newton de Lucena Costa ${ }^{*}$, Vicente Gianluppi ${ }^{2}$, Anibal de Moraes ${ }^{3}$, Paulo César \\ Faccio de Carvalho ${ }^{4}$, João Avelar Magalhães ${ }^{5}$, Amaury Burlamaqui Bendahan ${ }^{1}$
}

${ }^{1}$ Eng. Agr., D.Sc., Embrapa Roraima, Boa Vista, RR. *Autor para correspondência, E-mail: newton.lucena-costa@embrapa.br

${ }^{2}$ Eng. Agr., M.Sc., Embrapa Roraima, Boa Vista, RR.

${ }^{3}$ Professor, Departamento de Fitotecnia e Fitossanitarismo da Universidade Federal do Paraná, Curitiba, PR

${ }^{4}$ Professor, Departamento de Plantas Forrageiras e Agrometeorologia da Universidade Federal Rio Grande do Sul, Porto Alegre,

${ }^{5}$ Méd. Veterinário, D.Sc., Embrapa Meio Norte, Parnaiba, PI

RESUMO. O efeito de níveis de nitrogênio $\left(0,40,80,120,160\right.$ e $200 \mathrm{~kg}$ de $\left.\mathrm{N} \mathrm{ha}^{-1}\right)$ em pastagens puras de Trachypogon plumosus e o de densidades de semeadura de Stylosanthes capitata cv. Lavradeiro $\left(1,0 ; 2,0 ; 3,0\right.$ e 4,0 kg de sementes ha $\left.{ }^{-1}\right)$ sobre o rendimento de forragem, composição botânica e fixação e transferência aparentes de nitrogênio $(\mathrm{N})$ foi avaliado em condições de campo. A adubação nitrogenada afetou quadraticamente os rendimentos de forragem da gramínea e seus teores de nitrogênio, sendo os máximos valores estimados com a aplicação de 154,6 e 155,7 $\mathrm{kg}$ de $\mathrm{N} \mathrm{ha}^{-1}$, respectivamente. $\mathrm{O}$ rendimento de forragem da leguminosa é diretamente proporcional às densidades de sua semeadura, ocorrendo o oposto para a gramínea. Os rendimentos de forragem da consorciação, independentemente da densidade de semeadura da leguminosa, são superiores aos da gramínea em cultivo isolado e para todas as doses de $\mathrm{N}$ avaliadas. A utilização de densidades de semeadura entre 2,0 e $3,0 \mathrm{~kg} \mathrm{ha}^{-1}$ permitem o estabelecimento, a estabilidade produtiva e a persistência da consorciação. A fixação aparente de $\mathrm{N}$ pela leguminosa e sua transferência para a gramínea foram diretamente proporcionais às densidades de semeadura.

Palavras chave: Composição botânica, fixação e transferência de nitrogênio, matéria seca

\section{Nitrogen fertilization and intercropping of Trachypogon plumosus with Stylosanthes capitata cv. Lavradeiro under seeding densities}

ABSTRACT. The effect of nitrogen levels $(0,40,80,120,160$, and $200 \mathrm{~kg}$ of N ha $\left.{ }^{1}\right)$ on pure pastures of Trachypogon plumosus and the sowing densities of Stylosanthes capitata cv. Lavradeiro (1.0;2.0; 3.0 and $4.0 \mathrm{~kg}$ of seeds ha $\left.{ }^{-1}\right)$ on forage yield, botanical composition and apparent fixation and transfer of nitrogen $(\mathrm{N})$ was evaluated under field conditions. Nitrogen fertilization quadratically affected grass forage yields and its nitrogen content, and the maximum values were estimated by the application of 154.6 and $155.7 \mathrm{~kg} \mathrm{~N} \mathrm{ha}^{-1}$, respectively. The legume forage yield was directly proportional to the densities of its sowing, occurring the opposite for the grass forage yield. The forage yields of the grass-legume mixture, independently of legume sowing density, were higher than those showed by the grass grown alone and for all doses of $\mathrm{N}$ evaluated. The use of legume sowing densities between 2.0 
and $3.0 \mathrm{~kg} \mathrm{ha}^{-1}$ allows the establishment, the productive stability and the persistence of the grass-legume mixture. The apparent $\mathrm{N}$ fixation by the legume and its transfer to the grass were directly proportional to the legume sowing densities.

Keywords: Botanic composition, dry matter, $\mathrm{N}$-fixation, $\mathrm{N}$-transference

\title{
Fertilización nitrogenada y mezcla de Trachypogon plumosus con Stylosanthes capitata cv. Lavradeiro bajo diferentes densidades de siembra
}

\begin{abstract}
RESUMEN. El efecto de los niveles de nitrógeno (0, 40, 80, 120, 160 y $200 \mathrm{~kg} \mathrm{~N}$ $\mathrm{ha}^{-1}$ ) en pasturas puras de Trachypogon plumosus y de densidades de siembra de Stylosanthes capitata cv. Lavradeiro $\left(1,0 ; 2,0 ; 3,0\right.$ y 4,0 kg de semillas ha $\left.{ }^{-1}\right)$ en el rendimiento de forraje, composición botánica y la fijación y la transferencia aparentes de nitrógeno $(\mathrm{N})$ se evaluó en condiciones de campo. La fertilización nitrogenada afectó cuadráticamente los rendimientos de forraje e la gramínea y su contenido de nitrógeno, y los valores máximos estimados por la aplicación de 154,6 y $155,7 \mathrm{~kg} \mathrm{~N} \mathrm{ha}^{-1}$. El rendimiento de forraje de la fue directamente proporcional a la densidad de su siembra, el contrario ocurriendo con la productividad de la gramínea. Los rendimientos de forraje de la mezcla, independientemente de la densidad de siembra de la leguminosa, son más altos que en el cultivo de la gramínea aislado para todos los niveles de $\mathrm{N}$ evaluados. El uso de densidades de siembra de la leguminosa entre 2,0 y $3,0 \mathrm{~kg} \mathrm{ha}^{-1}$ permite el establecimiento, la estabilidad de producción y persistencia de la mezcla gramínea-leguminosa. La fijación aparente de nitrógeno por la leguminosa y su transferencia a la gramínea fueron directamente proporcional a densidades de siembra de la leguminosa.
\end{abstract}

Palabras clave: Composición botánica, fijación y transferencia de nitrógeno, materia seca

\section{Introdução}

Em Roraima, o fogo é uma prática comumente utilizada no manejo das pastagens nativas, pois apresenta baixo custo e fácil aplicação. Sua principal finalidade é a eliminação da biomassa seca acumulada e não consumida pelos animais durante o período de estiagem, proporcionando uma rebrota mais tenra, palatável e de melhor valor nutritivo. A queima incorpora todos os nutrientes não voláteis da biomassa, o que implica em aumento do $\mathrm{pH}$ e da fertilidade do solo, favorecendo o crescimento das pastagens. No entanto, a alta fertilidade é temporária, pois cerca de $97 \%$ do nitrogênio $(\mathrm{N}), 61 \%$ do fósforo $(\mathrm{P})$, $76 \%$ do potássio $(\mathrm{K})$ e $65 \%$ do cálcio $(\mathrm{Ca})$ e magnésio $(\mathrm{Mg})$ são transferidos para a atmosfera e apenas 21 a $34 \%$ do $\mathrm{Mg}, \mathrm{Ca}, \mathrm{K}$ e $\mathrm{P}$ e, $0,2 \%$ do $\mathrm{N}$ remanescem no solo sob a forma de cinzas (Hernández-Valencia and López-Hernández, 2002). O N pode ser perdido por lixiviação, volatilização ou imobilização, um processo onde o nutriente torna-se inutilizável pela planta, sendo a sua deficiência apontada como uma das principais causas para a baixa produtividade biológica primária das pastagens nativas (Braga, 1998, Costa et al., 2013).

As pastagens nativas, formadas quase que exclusivamente por gramíneas, necessitam de uma fonte para a reposição do $\mathrm{N}$ (química ou biológica), com o objetivo de manter a sua produção de forragem e assegurar a obtenção de índices zootécnicos satisfatórios (Gianluppi et al., 2001, Costa et al., 2009). O $\mathrm{N}$ é o principal nutriente para a manutenção da produtividade e persistência das gramíneas forrageiras, sendo constituinte das proteínas que participam ativamente na síntese dos compostos orgânicos que formam a estrutura do vegetal, além de maximizar as características morfogênicas (taxas de aparecimento, expansão e senescência das folhas) e estruturais da gramínea (tamanho de folha, densidade de perfilho e número de folhas por perfilho).

Nos solos deficientes em N, o crescimento e desenvolvimento das gramíneas tornam-se lentos, a produção de perfilhos é negativamente afetada e o teor de proteína torna-se deficiente para o atendimento das exigências do animal 
(Alexandrino et al., 2010, Brambilla et al., 2012). O melhoramento das pastagens nativas através da aplicação de fertilizantes nitrogenados pode ser inviável devido a seus altos custos, tornando-se necessário assegurar sua máxima eficiência, através da determinação das doses mais adequadas para o estabelecimento e manutenção das pastagens. A introdução de leguminosas surge como alternativa prática, eficiente e econômica para o fornecimento de $\mathrm{N}$ ao sistema solo-plantaanimal, além de aumentar a capacidade de suporte, melhorar o valor nutritivo da forragem e ampliar a estação de pastejo, refletindo positivamente na produção de carne e/ou leite (Townsend et al., 1999, Dias et al., 2007). Ademais, em face do melhor valor nutritivo em relação às gramíneas tropicais (maior conteúdo de nutrientes e melhor digestibilidade), as leguminosas favorecem o consumo de nutrientes digestíveis totais e da energia, elevando o desempenho animal, à medida que sua participação na pastagem aumenta (Minson and Milford, 1967). Deve-se ressaltar, ainda, o benefício que a gramínea consorciada recebe, em decorrência da transferência do $\mathrm{N}$ fixado via excreção direta de compostos nitrogenados pelas raízes, senescência de folhas das leguminosas e pelo animal em pastejo (fezes e urina).

Neste trabalho foram avaliados os efeitos da adubação nitrogenada sobre a produção de forragem de pastagens de Trachyogon plumosus, puras ou consorciadas com Stylosanthes capitata cv. Lavradeiro, sob diferentes densidades de semeadura.

\section{Material e Métodos}

O ensaio foi conduzido no Campo Experimental da Embrapa Roraima, localizado em Boa Vista, durante o período de junho de 2013 a setembro de 2014, em uma pastagem nativa onde a gramínea Trachypogon plumosus representava $95 \%$ de sua composição botânica. O clima da região, segundo a classificação de Köppen and Geiger (1928) é Awi, caracterizado por períodos seco e chuvoso bem definidos, com aproximadamente seis meses cada um. A precipitação média anual é de $1.600 \mathrm{~mm}$, sendo que $80 \%$ ocorrem nos seis meses do período chuvoso (abril a setembro). O solo da área experimental é um Latossolo Amarelo, textura média, com as seguintes características químicas, na profundidade de $0-20 \mathrm{~cm}: \mathrm{pH}_{\mathrm{H} 2 \mathrm{O}}=4,8 ; \mathrm{P}=1,9$ $\mathrm{mg} / \mathrm{kg} ; \mathrm{Ca}+\mathrm{Mg}=0,95 \mathrm{cmol}_{\mathrm{c} \cdot \mathrm{dm}^{-3}} ; \mathrm{K}=0,01$ $\mathrm{cmol}_{\mathrm{c}} \cdot \mathrm{dm}^{-3} ; \mathrm{Al}=0,61 \mathrm{cmol}_{\mathrm{c}} \mathrm{dm}^{-3} ; \mathrm{H}+\mathrm{Al}=2,64$ $\mathrm{cmol}_{\mathrm{c}} \cdot \mathrm{dm}^{-3}$ e SB $=0,96 \mathrm{cmol}_{\mathrm{c}} \cdot \mathrm{dm}^{-3}$.

$\mathrm{O}$ delineamento experimental foi inteiramente ao acaso com três repetições. Os tratamentos consistiram de seis doses de nitrogênio $(0,40,80$, 120,160 e $200 \mathrm{~kg} \mathrm{ha}^{-1}$ ) aplicadas na pastagem da gramínea em cultivo isolado e quatro densidades de semeadura da leguminosa $(1,0 ; 2,0 ; 3,0$ e $4,0 \mathrm{~kg}$ $\mathrm{ha}^{-1}$ - Valor Cultural $=100 \%$ ). A leguminosa utilizada foi Stylosanthes capitata cv. Lavradeiro, semeada a lanço e sem nenhum revolvimento do solo, após o rebaixamento da pastagem a $10 \mathrm{~cm}$ acima do solo. O tamanho das parcelas foi de 3,0 x 3,0 m, sendo a área útil de $4,0 \mathrm{~m}^{2}$. A adubação de estabelecimento constou da aplicação de $80 \mathrm{~kg}$ de $\mathrm{P}_{2} \mathrm{O}_{5} \mathrm{ha}^{-1}$ e $60 \mathrm{~kg} \mathrm{ha}^{-1}$ de $\mathrm{K}_{2} \mathrm{O}$, sob a forma de superfosfato triplo e cloreto de potássio, respectivamente, distribuídos a lanço quando da semeadura da leguminosa. Durante o período experimental foram realizados seis cortes a intervalos de 56 dias e a uma altura de $20 \mathrm{~cm}$ acima do solo.

Após a separação dos componentes gramínea e leguminosa, foi determinada a produção de matéria seca verde (MSV), a $65^{\circ} \mathrm{C}$ por 72 horas. $\mathrm{O}$ teor de nitrogênio foi determinado através do método micro-Kjeldhal. A estimativa da fixação aparente de nitrogênio foi obtida subtraindo-se o nitrogênio produzido pela consorciação do nitrogênio produzido com a gramínea em cultivo puro não fertilizado. A transferência de nitrogênio para a gramínea foi calculada subtraindo-se o nitrogênio fornecido pela gramínea componente de cada mistura pelo nitrogênio que produziu a gramínea em cultivo puro não fertilizada ( and Norris, 1962).

Os dados foram submetidos à análise de variância e de regressão considerando o nível de significância de $5 \%$ de probabilidade. Para se estimar a resposta dos parâmetros avaliados aos níveis de nitrogênio e densidades de semeadura, a escolha dos modelos de regressão baseou-se na significância dos coeficientes linear e quadrático, por meio do teste "t", de Student, ao nível de 5\% de probabilidade.

\section{Resultados e Discussão}

Os rendimentos de MSV da gramínea foram afetados $(\mathrm{P}<0,05)$ pela adubação nitrogenada, sendo a relação quadrática $(\mathrm{Y}=1.474+26,0065$ $\left.\mathrm{X}-0,0841 \mathrm{X}^{2}-\mathrm{R}^{2}=0,98\right)$ e a dose de máxima eficiência técnica estimada em $154,6 \mathrm{~kg}$ de $\mathrm{N} \mathrm{ha}^{-1}$ (3.483 kg de MSV ha ${ }^{-1}$ ) (Tabela 1). Rippstein et 
al. (2001) para Trachypogon vestitus, gramínea nativa dos cerrados da Colômbia e Cunha et al. (2001) em pastagens nativas do Rio Grande do Sul, reportaram efeitos lineares da adubação nitrogenada sobre o acúmulo de forragem com a aplicação de até 150 e $200 \mathrm{~kg}$ de $\mathrm{N} \mathrm{ha}^{-1}$ ano $^{-1}$, respectivamente. A adubação nitrogenada ao reduzir a respiração de manutenção e estimular a de crescimento - diretamente proporcional ao conteúdo proteico da planta e responsável pela produção de novos compostos orgânicos contribui positivamente para o maior acúmulo de biomassa (Gastal et al., 2010).
Os rendimentos de MSV da gramínea foram inversamente proporcionais às densidades de semeadura da leguminosa $(\mathrm{Y}=3.143-214,8 \mathrm{X}$; $\left.\mathrm{R}^{2}=0,89\right)$, ocorrendo $\mathrm{o}$ inverso quanto à disponibilidade da leguminosa $(\mathrm{Y}=1.116+178,4$ $\mathrm{X} ; \mathrm{R}^{2}=0,96$ ), enquanto que para a soma dos componentes (gramínea + leguminosa) não foi constatado efeito significativo $(\mathrm{P}>0,05)$ da densidade de semeadura (Tabela 1). Os rendimentos de MSV da gramínea registrados na consorciação estabelecida com densidade de semeadura de $1,0 \mathrm{~kg} \mathrm{ha}^{-1}$ foi semelhante à obtida com a gramínea em cultivo puro recebendo $40 \mathrm{~kg}$ de $\mathrm{N} \mathrm{ha}^{-1}$ (Tabela 1).

Tabela 1. Rendimento de matéria seca verde (MSV) e teores de nitrogênio de Trachypogon plumosus submetido a níveis de nitrogênio e em consorciação com Stylosanthes capitata cv. Lavradeiro (SC) sob densidades de semeadura $\left(\mathrm{D}_{1}=1,0 \mathrm{~kg}\right.$ sementes ha- ${ }^{-1} \mathrm{D}_{2}=2,0 \mathrm{~kg}$ sementes ha-1 $\mathrm{D}_{3}=3,0 \mathrm{~kg}$ sementes ha-1 e $\mathrm{D}_{4}=4,0 \mathrm{~kg}$ sementes ha-1). Médias de seis cortes.

\begin{tabular}{lccccc}
\hline Tratamentos & \multicolumn{3}{c}{ Rendimento de MSV $\left(\mathrm{kg} \mathrm{ha}^{-1}\right)$} & \multicolumn{2}{c}{ Teores de Nitrogênio $\left(\mathrm{g} \mathrm{kg}^{-1}\right)$} \\
\cline { 2 - 5 } & $\mathrm{TP}$ & $\mathrm{SC}$ & $\mathrm{T}$ & $\mathrm{T}$ & $\mathrm{SC}$ \\
\hline Trachypogon plumosus $(\mathrm{TP})$ & $1.378 \mathrm{e}$ & --- & $1.378 \mathrm{e}$ & $12,18 \mathrm{e}$ & --- \\
$\mathrm{TP}+40 \mathrm{~kg} \mathrm{~N} \mathrm{ha}^{-1}$ & $2.581 \mathrm{c}$ & --- & $2.581 \mathrm{~d}$ & $17,38 \mathrm{~cd}$ & --- \\
$\mathrm{TP}+80 \mathrm{~kg} \mathrm{~N} \mathrm{ha}^{-1}$ & $2.998 \mathrm{~b}$ & --- & $2.998 \mathrm{~cd}$ & $19,03 \mathrm{bc}$ & --- \\
$\mathrm{TP}+120 \mathrm{~kg} \mathrm{~N} \mathrm{ha}^{-1}$ & $3.205 \mathrm{ab}$ & --- & $3.205 \mathrm{bc}$ & $21,67 \mathrm{a}$ & --- \\
$\mathrm{TP}+160 \mathrm{~kg} \mathrm{~N} \mathrm{ha}^{-1}$ & $3.579 \mathrm{a}$ & --- & $3.579 \mathrm{~b}$ & $20,89 \mathrm{ab}$ & --- \\
$\mathrm{TP}+200 \mathrm{~kg} \mathrm{~N} \mathrm{ha}^{-1}$ & $3.309 \mathrm{a}$ & --- & $3.309 \mathrm{bc}$ & $20,31 \mathrm{ab}$ & --- \\
$\mathrm{TP}+\mathrm{SC}-\mathrm{D}_{1}$ & $2.981 \mathrm{~b}$ & $1.301 \mathrm{c}$ & $4.282 \mathrm{a}(30,4)$ & $15,90 \mathrm{~d}$ & $27,37 \mathrm{a}$ \\
$\mathrm{TP}+\mathrm{SC}-\mathrm{D}_{2}$ & $2.567 \mathrm{c}$ & $1.489 \mathrm{~b}$ & $4.056 \mathrm{a}(36,7)$ & $16,31 \mathrm{~d}$ & $27,18 \mathrm{a}$ \\
$\mathrm{TP}+\mathrm{SC}-\mathrm{D}_{3}$ & $2.633 \mathrm{c}$ & $1.599 \mathrm{~b}$ & $4.232 \mathrm{a}(37,8)$ & $16,97 \mathrm{~cd}$ & $28,79 \mathrm{a}$ \\
$\mathrm{TP}+\mathrm{SC}-\mathrm{D}_{4}$ & $2.243 \mathrm{~d}$ & $1.859 \mathrm{a}$ & $4.102 \mathrm{a}(45,3)$ & $17,25 \mathrm{~cd}$ & $27,82 \mathrm{a}$ \\
\hline $\mathrm{M}$
\end{tabular}

Médias seguidas de mesma letra não diferem entre si $(\mathrm{P}>0,05)$ pelo teste de Tukey.

*Percentual da leguminosa em relação ao rendimento total de MSV.

A participação da leguminosa na composição botânica da pastagem foi diretamente proporcional às densidades de semeadura $(30,4$; 36,$7 ; 37,8$ e $45,3 \%$, respectivamente para 1,$0 ; 2,0$; 3,0 e $\left.4,0 \mathrm{~kg} \mathrm{ha}^{-1}\right)$. Visando potencializar os benefícios decorrentes da introdução de leguminosas em pastagens monoespecíficas de gramíneas, em termos de fixação biológica de nitrogênio, reciclagem de nutrientes, valor nutritivo da forragem em oferta e maior eficiência de pastejo, recomenda-se como proporção adequada 20 a $40 \%$ da leguminosa (Townsend et al., 1999). Neste contexto, a utilização de densidades de semeadura entre 2,0 e $3,0 \mathrm{~kg} \mathrm{ha}^{-1}$ permitem o estabelecimento, a estabilidade produtiva e a persistência da consorciação. Costa (2004) avaliando métodos de sobressemeadura de Desmodium ovalifolium CIAT-350 em pastagens de Andropogon gayanus cv. Planaltina constatou que o plantio a lanço e densidade de semeadura de $2,5 \mathrm{~kg} \mathrm{ha}^{-1}($ Valor cultural $=100 \%)$ proporcionou maiores rendimentos de forragem da gramínea
(4.357 kg ha-1 de MS) e da consorciação $(6.121 \mathrm{~kg}$ ha $^{-1}$ de MS). A utilização de densidades superiores a 3,0 $\mathrm{kg} \mathrm{ha}^{-1}$ de sementes da leguminosa suprimiu o crescimento da gramínea (1.876 $\mathrm{kg} \mathrm{ha}^{-1} \mathrm{de}$ MS) e resultou em completa dominância da leguminosa (5.078 $\mathrm{kg} \mathrm{ha}^{-1}$ de MS).

$\mathrm{O}$ efeito da adubação nitrogenada sobre os teores de $\mathrm{N}$ da gramínea foi ajustado ao modelo quadrático $\left(\mathrm{Y}=12,43+0,1246 \mathrm{X}-0,000413 \mathrm{X}^{2}\right.$; $\left.\mathrm{R}^{2}=0,94\right)$ e o máximo valor estimado com a

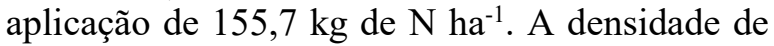
semeadura da leguminosa afetou positiva $\mathrm{e}$ linearmente o teor de $\mathrm{N}$ da gramínea $(\mathrm{Y}=15,43+$ $\left.0,4711 \mathrm{X} ; \mathrm{R}^{2}=0,97\right)$, não sendo constatado efeito significativo $(\mathrm{P}>0,05)$ para o teor de $\mathrm{N}$ da leguminosa (Tabela 1). Townsend et al. (1999) constataram reduções nos teores de PB e P de Urochloa. brizantha cv. Marandu com o aumento da densidade de semeadura de Pueraria phaseoloides, ocorrendo o oposto quanto aos teores da leguminosa. Em pastagens de $U$. 
decumbens sobressemeadas com Stylosanthes guianensis + Stylosanthes capitata cv. Campo Grande, Fabrice et al. (2015) reportaram maiores teores de PB para a gramínea consorciada $(10,8 \%)$, comparativamente ao seu cultivo estreme (6,97\%); contudo não foi observado efeito positivo da adubação fosfatada $(8,44$ e $8,48 \%$, respectivamente para 0 e $60 \mathrm{~kg}$ de $\left.\mathrm{P}_{2} \mathrm{O}_{5} \mathrm{ha}^{-1}\right)$. Costa (2004), em pastagens de U. brizantha cv. Xaraés consorciadas com $S$. capitata cv. Capica relatou que os teores de PB da gramínea $(8,3 ; 9,5$ e $11,1 \%$ ) foram diretamente proporcionais à percentagem da leguminosa na consorciação $(29,5 ; 33,1$ e 40,8\%). Moreira et al. (2013) estimaram maiores teores de $\mathrm{PB}(12,4 \%)$ e de $\mathrm{P}$ $\left(3,98 \mathrm{~g} \mathrm{~kg}^{-1}\right)$ para $U$. brizantha cv. Marandu consorciada com $S$. guianensis, relativamente à gramínea em cultivo isolado (10,6\% de PB e 3,19 $\mathrm{g} \mathrm{kg}^{-1}$ de P).

Os teores de $\mathrm{N}$ da gramínea, independentemente dos níveis de adubação nitrogenada, foram inferiores ao sugerido por Jeuffroy et al. (2002) como adequado para a manutenção da capacidade de fixação de carbono $\mathrm{e}$, consequentemente da produtividade biológica primária da gramínea $\left(30 \mathrm{~g} \mathrm{~kg}^{-1}\right)$. Considerando-se que teores de $\mathrm{N}$ inferiores a $11,2 \mathrm{~g} \mathrm{~kg}^{-1}$ são limitantes para que ocorra uma adequada fermentação ruminal, implicando em menor consumo voluntário, redução na digestibilidade da forragem e balanço nitrogenado negativo, a gramínea atenderia, satisfatoriamente, aos requerimentos mínimos dos ruminantes, independentemente do nível de adubação nitrogenada.

A fixação aparente de $\mathrm{N}$ e sua transferência para a gramínea foi diretamente proporcional às densidades de semeadura da leguminosa (Tabela 2). As quantidades fixadas de $\mathrm{N}$ foram semelhantes às reportadas por Costa (1995) para pastagens de Pennisetum purpureum cv. Cameroon consorciadas com Centrosema macrocarpum $\left(46,11 \mathrm{~kg} \mathrm{ha}^{-1}\right)$, C. pubescens $\left(47,92 \mathrm{~kg} \mathrm{ha}^{-1}\right)$ e Calopogonium mucunoides $\left(44,40 \mathrm{~kg} \mathrm{ha}^{-1}\right)$. Costa (2004) e Carvalho and Pires (2008) avaliando diversas consorciações de gramíneas e leguminosas forrageiras tropicais, constataram que a fixação e transferência aparentes de nitrogênio estiveram diretamente relacionadas com a participação das leguminosas na mistura. No presente trabalho, observou-se uma alta correlação positiva entre a percentagem de leguminosas na consorciação e a fixação de nitrogênio $(\mathrm{r}=0,93 * *)$. Para $\underline{\operatorname{Simpson}(1976)}$, a transferência de $\mathrm{N}$ para a gramínea associada aumenta à medida que as leguminosas se tornam menos persistentes na pastagem, já que a senescência e/ou queda de folhas é um dos mecanismos de transferência mais importantes. Jones et al. (1967) e Miller and der List (1977) estimaram que para Macroptilium atropurpureum, Desmodium intortum e Lotononis bainesii, este mecanismo foi responsável pela transferência de 29, 32 e 13\%, respectivamente do nitrogênio fixado para a gramínea consorciada. Para pastagens de Digitaria setivalva cv. Survenola, a transferência de $\mathrm{N}$ das leguminosas para a gramínea foi de 29,$9 ; 37,7$ e $28 \%$ do total acumulado pela gramínea, equivalente a 22,0; 16,7 e $8,2 \mathrm{~kg} \mathrm{ha}^{-1}$ de $\mathrm{N}$ para Enterolobium contortisiliquum, Dalbergia nigrae Peltophorum dubium, respectivamente.

Tabela 2. Estimativa das quantidades de nitrogênio fixadas e transferidas pela leguminosa para a gramínea, em função da densidade de semeadura da leguminosa $(\mathrm{D} 1=1,0 \mathrm{~kg}$ sementes $\mathrm{ha}^{-1} ; \mathrm{D} 2=2,0 \mathrm{~kg}$ sementes $\mathrm{ha}^{-1} ; \mathrm{D} 3=3,0 \mathrm{~kg}$ sementes ha ${ }^{-1}$ e D4 $=4,0 \mathrm{~kg}$ sementes ha-1)

\begin{tabular}{ccccc}
\hline $\begin{array}{c}\text { Densidades de } \\
\text { Semeadura da } \\
\text { Leguminosa }\end{array}$ & $\begin{array}{c}\text { Nitrogênio fixado } \\
\mathrm{kg} \mathrm{ha}^{-1} \mathrm{ano}^{-1}\end{array}$ & \multicolumn{2}{l}{$\begin{array}{c}\text { Nitrogênio transferido } \\
\mathrm{kg} \mathrm{ha}^{-1} \mathrm{ano}^{-1}\end{array} \%$} \\
\hline D1 & $35,62 \mathrm{~d}$ & $11,57 \mathrm{c}$ & 32,51 \\
D2 & $40,48 \mathrm{c}$ & $14,53 \mathrm{c}$ & 35,90 \\
D3 & $46,00 \mathrm{~b}$ & $18,87 \mathrm{~b}$ & 41,07 \\
D4 & $51,72 \mathrm{a}$ & $22,55 \mathrm{a}$ & 43,62 \\
\hline
\end{tabular}

Médias seguidas de mesma letra não diferem entre si ( $\mathrm{P}>$ $0,05)$ pelo teste de Tukey

\section{Conclusões}

A adubação nitrogenada afeta positivamente o rendimento e a qualidade de forragem da gramínea em cultivo isolado.

O rendimento de forragem da leguminosa é diretamente proporcional às densidades de sua semeadura, ocorrendo o oposto para a gramínea.

Os rendimentos de forragem da consorciação, independentemente da densidade de semeadura da leguminosa, são superiores aos da gramínea em cultivo isolado e para todas as doses de $\mathrm{N}$.

A utilização de densidades de semeadura entre 2,0 e $3,0 \mathrm{~kg} \mathrm{ha}^{-1}$ permitem o estabelecimento, a estabilidade produtiva e a persistência da consorciação.

A fixação aparente de $\mathrm{N}$ pela leguminosa e sua transferência para a gramínea são diretamente proporcionais às densidades de semeadura.

Referências Bibliográficas 
Alexandrino, E., Vaz, R. G. M. V. \& Santos, A. C. 2010. Characteristics of Brachiaria brizantha $\mathrm{cv}$. marandu during the establishment assigned of differents levels of nitrogen. Bioscience Journal, 26, 886-893.

Braga, R. M. 1998. A Agropecuária em Roraima: considerações históricas, de produção e geração de conhecimentos. Boa Vista: Embrapa Roraima. 63p. (Documentos, 1).

Brambilla, D. M., Nabinger, C., Kunrath, T. R., Carvalho, P. C. F., Carassai, I. J. \& Cadenazzi, M. 2012. Impact of nitrogen fertilization on the forage characteristics and beef calf performance on native pasture overseeded with ryegrass. Revista Brasileira de Zootecnia, 41, 528-536.

Carvalho, G. G. P. \& Pires, A. J. V. 2008. Herbaceous tropical legumes associated with pasture. Archivos de Zootecnia, 57, 103-113.

Costa, N. L. 1995. Adubação nitrogenada e consorciação de capim-elefante (Pennisetum purpureum cv. Cameroon) com leguminosas forrageiras tropicais. Pesquisa Agropecuária Brasileira, 30, 401-408.

Costa, N. L. 2004. Formação, manejo e recuperação de pastagens em Rondônia. Porto Velho: Embrapa Rondônia, 217p.

Costa, N. L., Gianluppi, V., Braga, R. M. \& Bendahan, A. B. 2009. Alternativas tecnológicas para a pecuária de Roraima. Boa Vista: Embrapa Roraima, 35p. (Documentos, 19).

Costa, N. L., Moraes, A., Carvalho, P. C. F., Monteiro, A. L. G., Motta, A. C. V. \& Oliveira, R. A. 2013. Composição e extração de nutrientes por Trachypogon plumosus sob adubação e idades de rebrota. Archivos de Zootecnia, 62, 227-238.

Cunha, M. K., Siewerdt, L., Silveira Jr, P. \& Siewerdt, F. 2001. Doses de nitrogênio e enxofre na produção e qualidade da forragem de campo natural de planossolo no Rio Grande do Sul. Revista Brasileira de Zootecnia, 30, 651-658.

Dias, P. F. S., Resende, S. M., Joventino, A. S., Urquiaga, S., Rocha, G. P., Moreira, J. F. \& Franco, A. A. 2007. Transferência do N fixado por leguminosas arbóreas para o capim Survenola crescido em consórcio. Ciência Rural, 37, 352-356.
Fabrice, C. E. S., Soares Filho, C. V., Pinto, M. F., Perri, S. H. V., Cecato, U. \& Mateus, G. P. 2015. Recuperação de pastagens de" Brachiaria decumbens" degradada com introdução de Stylosanthes e adubação fosfatada. Revista Brasileira de Saúde e Produção Animal, 16, 758-771.

Gastal, F., Dawson, L. A. \& Thornton, B. 2010. Responses of plant traits of four grasses from contrasting habitats to defoliation and $\mathrm{N}$ supply. Nutrient Cycling in Agroecosystems, 88, 245-258.

Gianluppi, D., Gianluppi, V. \& Smiderle, O. 2001. Produção de pastagens nos cerrados de Roraima. Boa Vista: Embrapa Roraima, 4p. (Comunicado Técnico, 14).

Henzell, E. F. \& Norris, D. O. 1962. Processes by which nitrogen is added to the soil/plant system. Commonwealth Bureau of Pastures and Field Crops, Bulletin, 1, 1-18.

Hernández-Valencia, I. \& López-Hernández, D. 2002. Pérdida de nutrimentos por la quema de la vegetación en una sabana de Trachypogon. Revista de Biología Tropical, 50, 1013-1019.

Jeuffroy, M. H., Ney, B. \& Ourry, A. 2002. Integrated physiological and agronomic modelling of $\mathrm{N}$ capture and use within the plant. Journal of Experimental Botany, 53, 809-823.

Jones, R. J., Griffiths, D. J. \& Waite, R. B. 1967. The contribution of some tropical legumes to pasture yields of dry matter and nitrogen at Samford, south-eastern Queensland. Animal Production Science, 7, 57-65.

Köppen, W. \& Geiger, R. 1928. Klimate der Erde. Gotha: Verlag Justus Perthes. Wall-map $150 \mathrm{~cm} \times 200 \mathrm{~cm}$.

Miller, C. P. \& der List, J. T. 1977. Yield, nitrogen uptake and liveweight gains from irrigated grass-legume pasture on a Queensland tropical highland. Animal Production Science, 17, 949960 .

Minson, D. J. \& Milford, R. 1967. Intake and crude protein content of mature Digitaria decumbens and Medicago sativa. Australian Journal of Experimental Agriculture and Animal Husbandry, 7, 546-551.

Moreira, J. F. M., Costa, K. A. P., Severiano, E. C., Simon, G. A., Cruvinel, W. S. \& Bento, J. C. 2013. Nutrientes em cultivares de 
Brachiaria brizantha e estilosantes em cultivo solteiro e consorciado. Archivos de Zootecnia, $62,513-523$.

Rippstein, G., Escobar, G. \& Motta, F. M. 2001. Agroecología y biodiversidad de las sabanas en los Llanos Orientales de Colombia. CIAT, Bogotá. 302p.

Simpson, J. R. 1976. Transfer of nitrogen from three pasture legumes under periodic defoliation in a field environment. Animal Production Science, 16, 863-870.

Townsend, C. R., Costa, N. L., Pereira, R. G. A. \& Magalhães, J. A. 1999. Métodos de plantio e densidades de semeadura no estabelecimento de leguminosas em pastagens degradadas na Amazônia Ocidental. Porto Velho: Embrapa Rondônia, 4p. (Comunicado Técnico, 175).

Article History:

Received 05 May 2017

Accepted 28 May 2017

Available on line 6 July 2017

License information: This is an open-access article distributed under the terms of the Creative Commons Attribution License 4.0, which permits unrestricted use, distribution, and reproduction in any medium, provided the original work is properly cited. 